\title{
Experimental Investigation of Injection-Coupled High-Frequency Combustion Instabilities
}

\author{
Wolfgang Armbruster, Justin S. Hardi, and Michael Oschwald
}

\begin{abstract}
Self-excited high-frequency combustion instabilities were investigated in a 42-injector cryogenic rocket combustor under representative conditions. In previous research it was found that the instabilities are connected to acoustic resonance of the shear-coaxial injectors. In order to gain a better understanding of the flame dynamics during instabilities, an optical access window was realised in the research combustor. This allowed 2D visualisation of supercritical flame response to acoustics under conditions similar to those found in European launcher engines. Through the window, high-speed imaging of the flame was conducted. Dynamic Mode Decomposition was applied to analyse the flame dynamics at specific frequencies, and was able to isolate the flame response to injector or combustion chamber acoustic modes. The flame response at the eigenfrequencies of the oxygen injectors showed symmetric and longitudinal wave-like structures on the dense oxygen core. With the gained understanding of the BKD coupling mechanism it was possible to derive LOX injector geometry changes in order to reduce the risks of injection-coupled instabilities for future cryogenic rocket engines.
\end{abstract}

\section{Introduction}

Several phenomena in the combustion chamber of liquid propellant rocket engines (LPREs) are investigated in division $\mathrm{C}$ of the SFB TRR40. Among those, highfrequency combustion instabilities are one of the most challenging and dangerous effects which can occur in the development of new rocket engines [15, 26, 30]. A well-known example of combustion instabilities is the F-1 engine of the Saturn V

W. Armbruster $(\varangle) \cdot$ J. S. Hardi $\cdot$ M. Oschwald

DLR Institute of Space Propulsion, 74239 Hardthausen, Germany

e-mail: Wolfgang.Armbruster@dlr.de

J. S. Hardi

e-mail: Justin.Hardi@dlr.de

M. Oschwald

e-mail: Michael.Oschwald@dlr.de

(C) The Author(s) 2021 
rocket [20]. More than 2000 full-scale engine tests and several injector designs were necessary to find a stable design.

Combustion instabilities emerge by interaction of combustion chamber acoustics and heat release oscillations. As described by Rayleigh in 1878 [22], pressure oscillations can grow if they are in phase with heat release rate oscillations. The underlying mechanisms coupling pressure and heat release rate oscillations in rocket combustion chambers are still not fully understood today [15], confirmed by the example of the Japanese liquid oxygen-hydrogen $\left(\mathrm{LOX} / \mathrm{H}_{2}\right)$ main stage engine LE-9, which also faced instability issues during development [28].

The coupling mechanisms are often divided into combustion-chamber instabilities and injection-coupled mechanisms. Combustion-chamber mechanisms are defined by processes only happening inside the combustion chamber, such as atomization, mixing and combustion [10]. For injection-coupled mechanisms, mass flow rate oscillations originating from acoustic resonance in the injector elements interact with the chamber acoustics [30].

So far the detailed physical processes of injection-coupling are not fully understood. It is, for example, not known how the flames react to the pressure oscillations in the injectors. Simulations of supercritical coaxial flames indicated different responses of the LOX core to injected mass flow oscillations and chamber pressure oscillations [3, 12, 18, 27]. However, to the authors' knowledge, there are no validation data for these simulations from experiments with representative conditions, such as supercritical combustion and self-excited oscillations. These reasons motivated the study of dynamic flame response to injector oscillations presented here.

\subsection{Summary of Previous Investigations}

The investigation of flame response began in the preceding funding period of the TRR40 on the basis of flame radiation observed via fibre-optical probes. Self-excited combustion instabilities of the first tangential (1T) resonance mode can be reproduced in a sub-scale research thrust chamber designated 'BKD'. BKD runs with the cryogenic propellant combination $\mathrm{LOX} / \mathrm{H}_{2}$ injected through 42 shear-coaxial injectors and operates at supercritical pressures for oxygen. A major aspect of the experimental investigation with BKD was the analysis of the optical probe signals, which showed that flame radiation intensity fluctuates with frequencies corresponding to those of the LOX injectors [9-11]. The interpretation of these data has been substantially supported by experimental and numerical hydrogen-oxygen flame radiation investigations done at the TU Munich (TUM), also within the C7 division of the TRR40. 


\subsubsection{Combustion Instability at DLR}

The combustion instability in BKD appears at specific operating conditions, or load points (LPs), of the combustion chamber which are defined by the combustion chamber pressure $\left(p_{c c}\right)$, the propellant mixture ratio $\left(\mathrm{ROF}=\dot{m}_{\mathrm{O} 2} / \dot{m}_{\mathrm{H}_{2}}\right)$, and the hydrogen and oxygen temperatures ( $T_{H 2}$ and $T_{O 2}$, respectively). The observed instability is the result of an amplification of the first tangential (1T) resonance mode of the chamber, reaching peak-to-peak amplitudes of up to $43 \%$ of $p_{c c}$ [10]. A parameter study of different operating conditions showed that ROF and $T_{H_{2}}$ have a strong impact on the resonance frequencies of the combustor, while the influence of $p_{c c}$ is low $[9,10]$.

The measurement of the $\mathrm{OH}^{*}$ radiation intensity using fibre-optical probes showed dominant frequencies in the flame dynamics which did not match the resonance frequencies of the combustion chamber [10]. The instability occurs when the $1 \mathrm{~T}$ frequency of the combustion chamber matches one of the dominant frequencies of the heat release fluctuations of the flame, as shown in Fig. 1.

It was proven that the dominant frequencies of the $\mathrm{OH}^{*}$ fluctuation correspond to the resonance frequencies of the LOX posts of the injectors [10]. For specific LPs, the $1 \mathrm{~T}$ mode has a frequency which matches the second eigenfrequency of the LOX posts and thus one of the dominant frequencies of the heat release oscillations of the flame. This enables the Rayleigh criterion [22] to be fulfilled. This type of coupling mechanism is referred to as injection-coupling and has also been observed in sub-scale experiments $[17,19,30]$ up to full-scale main stage engines [28, 30]. Therefore, it is a rather common type of coupling mechanism for cryogenic LPREs and a better understanding of the processes involved is necessary in order to be able to prevent it in future European rocket engines.

Fig. 1 Dependence of the averaged amplitude of the $1 \mathrm{~T}$ mode on the spacing between the $1 \mathrm{~T}$ mode frequency and the second dominant frequency in $\mathrm{OH}^{*}$ radiation fluctuations [9]

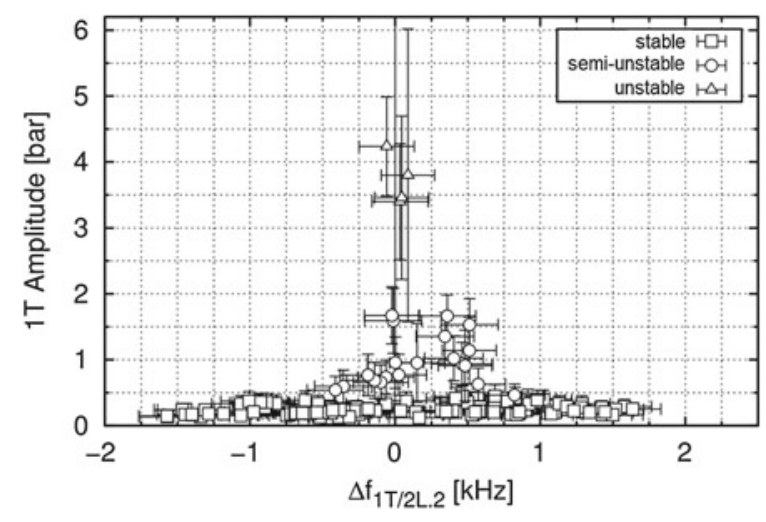




\subsubsection{Flame Radiation at TUM}

Parallel to the work on a practical combustion instability in BKD at DLR, the fundamental properties of radiation from $\mathrm{LOX} / \mathrm{H}_{2}$ flames were studied at TUM. Flame visualisation in the UV, filtered for $\mathrm{OH}^{*}$ wavelengths around $308 \mathrm{~nm}$ [8], is common for the propellant combination oxygen-hydrogen. High-speed $\mathrm{OH}^{*}$ radiation imaging has also already widely been used to study acoustic-flame interaction [13, 23 ] within the field of instability research. One of the key contributions to the understanding of the instability mechanism of BKD was the analysis of the flame radiation intensity using the fibre-optical probes.

However, there is no easy way to quantitatively describe the relationship between flame emission and heat release. For this reason, the flame radiation of hydrogenoxygen combustion under conditions found in LPREs, namely high pressures and temperatures, was extensively investigated at TUM.

The spectrally and spatially resolved flame emission spectra of a laminar $\mathrm{H}_{2}-\mathrm{O}_{2}$ flame revealed characteristics of $\mathrm{OH}^{*}$ radiation complicating the interpretation of the flame imaging. Thermally excited $\mathrm{OH}^{*}$ emission predominates chemiluminescence at temperatures above $2700 \mathrm{~K}$ [5-7]. In addition, self-absorption significantly influences line-of-sight integrated $\mathrm{OH}^{*}$ radiation at high pressures, so the measurement is dominated by emission at the flame surface closest to the observer [6].

The blue region of oxygen-hydrogen flame spectra, which is broad with a peak between 420 and $440 \mathrm{~nm}$, was also investigated [5]. At ambient pressure, the blue radiation is very weak, but at high pressures it has a higher intensity than $\mathrm{OH}^{*}$. In comparison to $\mathrm{OH}^{*}$, the blue radiation does not noticeably suffer from self-absorption. Visualisation with $\mathrm{OH}^{*}$ radiation can be well complemented by measurements of blue radiation [7].

In addition, heat release rate was extracted from numerical simulations. For laminar flames, no spatial correlation of heat release and radiation was observed [5]. Theoretical considerations and flamelet simulations showed that there is also no general correlation between heat release rate and radiation for turbulent flames [5]. Pressure and strain rate distributions have a considerable impact on this correlation. However, if both of these parameters are assumed to be quasi-steady state, the assumption of local proportionality between radiation and heat release rate can be justified.

\section{Experimental Technique}

The main results of Gröning et al. in the preceding TRR40 funding period were mostly based on fibre-optical probes in the measurement ring [9-11]. However, important research questions could not be answered by line-of-sight integrated 1D flame radiation measurements. In other experiments with less challenging environments than BKD, optical access has successfully been applied [13, 14, 21, 23, 29]. In these 
Fig. 2 Thrust chamber BKD [1]

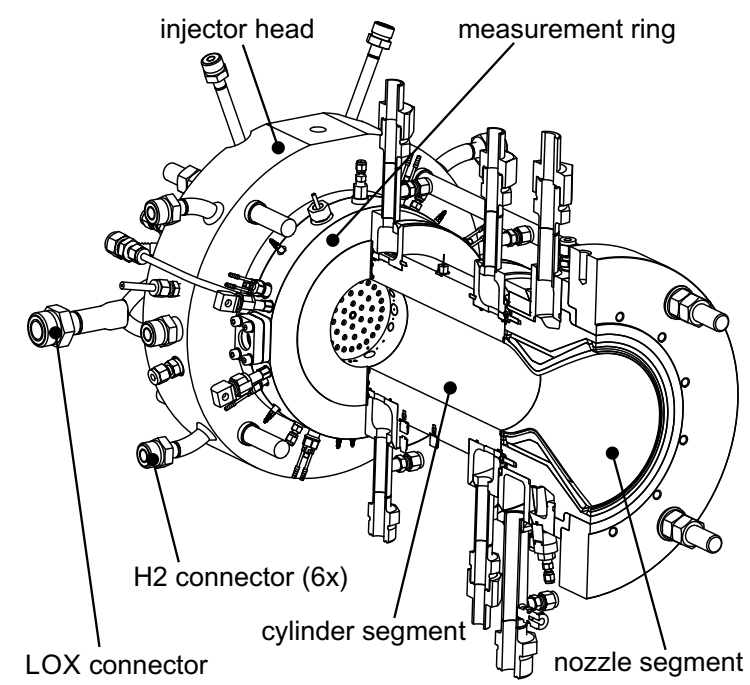

experiments, high-speed flame visualisation allowed further insight into the flame response to acoustic oscillations.

For that reason, the current TRR40 funding period was used to increase the optically accessible area of the BKD combustion chamber, allowing 2D flame visualisation. A new round of hot-fire tests with BKD were conducted at the DLR test bench P8. The combustor, as well as the optical diagnostics and the mathematical method to extract the relevant flame dynamics, are described in this section.

\subsection{Experimental Setup}

\subsubsection{Combustor}

The combustor used in this investigation is the DLR research thrust chamber model ' $\mathrm{D}$ ' (BKD). BKD is a conventional LPRE thrust chamber with a multi-element injector head, a cylindrical chamber with an inner diameter of $80 \mathrm{~mm}$, and a convergentdivergent nozzle. A measurement ring containing the majority of the diagnostics is placed between the injector head and the cylindrical chamber segment. In order to achieve optical access into the combustion chamber, a new water-cooled measurement ring was designed.

The injector head consists of 42 shear coaxial injection elements with recessed and tapered LOX posts. The inner diameter of the LOX posts is $3.6 \mathrm{~mm}$ and the length of the posts is $68 \mathrm{~mm}$. 
Fig. 3 BKD test sequence for configuration with optical access window. The investigated load point (LP) around $10.5 \mathrm{~s}$ is also indicated

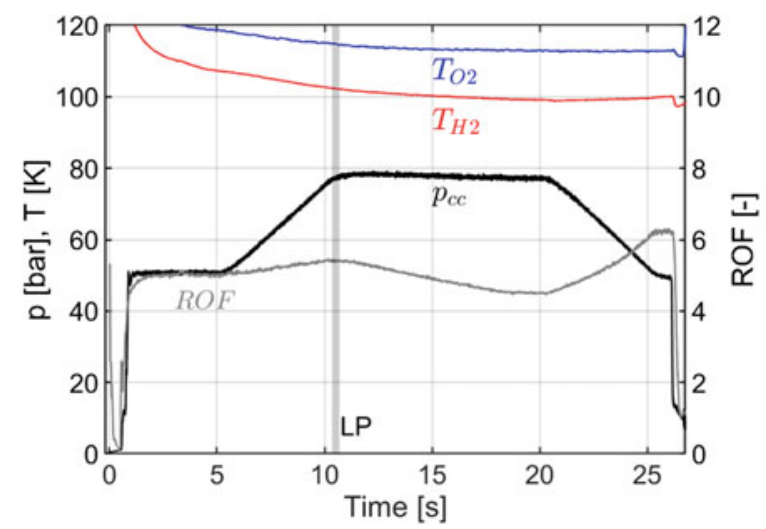

Table 1 Chamber operating conditions for the investigated load point

\begin{tabular}{l|l|l|l}
\hline Description & Variable & Unit & Mean value \\
\hline $\begin{array}{l}\text { Combustion chamber } \\
\text { pressure }\end{array}$ & $p_{c c}$ & {$[\mathrm{bar}]$} & 77.6 \\
\hline $\begin{array}{l}\text { Propellant mixture } \\
\text { ratio }\end{array}$ & $\mathrm{ROF}^{\mathrm{a}}$ & {$[-]$} & 5.3 \\
\hline $\begin{array}{l}\text { Hydrogen injection } \\
\text { temperature }\end{array}$ & $T_{H 2}$ & {$[\mathrm{~K}]$} & 102 \\
\hline $\begin{array}{l}\text { LOX injection } \\
\text { temperature }\end{array}$ & $T_{O 2}$ & {$[\mathrm{~K}]$} & 115 \\
\hline Momentum flux ratio & $J$ & {$[-]$} & 21 \\
\hline
\end{tabular}

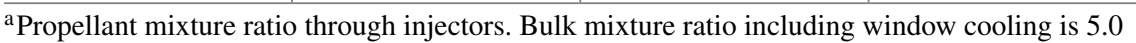

\subsubsection{Operating Conditions}

Figure 3 shows a typical test sequence of BKD with the optical access window. The LP for this study is also highlighted and was chosen around $10.5 \mathrm{~s}$, based on the highest ROF and also the greatest pressure and intensity dynamics in the frequency range around $10 \mathrm{kHz}$. The chamber and injection conditions for the LP are summarised in Table 1.

\subsubsection{Measurement Technique}

The harsh conditions inside the combustion chamber restricts possible sensor positions. Most of the diagnostics are placed between the injector head and the cylindrical combustion chamber segment in a so-called 'measurement ring'. The measurement ring, as shown in Fig. 4, contains eight Kistler pressure oscillation sensors, and two static pressure measurement ports. Fibre-optical probes measuring $\mathrm{OH}^{*}$ oscillations of individual flames are also included. 
Fig. 4 Measurement ring with optical access

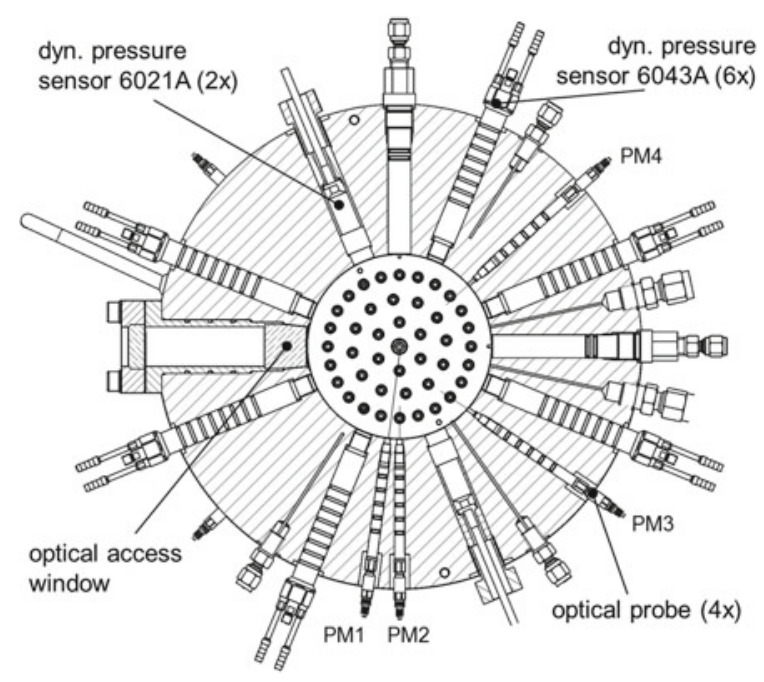

The new measurement ring developed for this work also facilitates $2 \mathrm{D}$ flame visualisation through an optical access window into BKD. The length of the window is restricted by the rapidly increasing thermal loads along the chamber axis. Modelling results from TUM [25], such as the temperature and heat release rate distribution, were helpful in the design of the window. The resulting window has a diameter of $18 \mathrm{~mm}$. The URANS model of a single BKD flame by Schulze [25] indicated that about $45 \%$ of the integrated Rayleigh driving appears in the first $15 \mathrm{~mm}$ of BKD. Thus the window dimensions should allow the observations of a significant portion of the total thermoacoustic coupling.

The position of the sapphire window in the measurement ring with respect to the injector pattern can be seen in Fig. 4. One of the outer injectors is aligned with the centre of the window.

Simultaneous high-speed imaging of the conventional $\mathrm{OH}^{*}$ radiation $(310 \pm$ $5 \mathrm{~nm})$ and also the blue radiation $(436 \pm 5 \mathrm{~nm})$ was conducted. The high-speed cameras were both operated with 60,000 frames per second (FPS), which leads to about six images per instability cycle.

\subsection{Methodology}

Dynamic mode decomposition (DMD) as described by Schmid et al. [24] allows the extraction of periodically fluctuating phenomena at specific frequencies from a series of images. DMD was applied to the high-speed flame radiation data in order to investigate the flame dynamics at the frequencies of interest. The DMD method has 
been used in past thermoacoustic instability research in order to extract the response of rocket combustor flames from visualisation data [3, 14, 16, 29].

Each DMD mode is defined by a temporal component that describes how the mode oscillates in time and a spatial mode including the information of the intensity fluctuation of each pixel around the mean value. The DMD mode magnitude is calculated as the Euclidean norm of the spatial modes and can be plotted over frequency in order to identify modes with highest coherence in the high-speed imaging data. A more detailed description of the DMD method is given by Beinke [4]. In this work, blue radiation and $\mathrm{OH}^{*}$ data over periods of $0.1 \mathrm{~s}$ or 6000 images were processed, yielding a frequency resolution of $10 \mathrm{~Hz}$ in the DMD spectrum.

From previous studies of the BKD instability mechanism, the modes of interest are already known $[9,10]$. The focus of this study is a detailed investigation of the flame response to the excited injector acoustics. The spatial mode shapes of the flame response to the LOX injector acoustics have been investigated and published [2].

To gain a better qualitative understanding of the flame response to the injector acoustics, the relevant DMD modes can be combined with the mean image from the same set of frames. However, compared to the intensity of the mean image, the intensity of each DMD mode is relatively low. For visualisation purposes, the intensity of the spatial component of the DMD mode was increased by a factor of 10. It is important to note that this artificial increase of DMD mode intensity with respect to the mean image does not change the spatial distribution or phase.

\section{Results and Discussion}

\subsection{Mean Flame Images}

The mean images for the investigated load point can be found in Fig. 5. In the $\mathrm{OH}^{*}$ radiation image on the left hand side of Fig. 5, one can mainly see the outer surface of the reaction zone due to the strong-self-absorption of $\mathrm{OH}^{*}$. The intensity field quickly becomes more uniform progressing downstream, which indicates interaction with neighbouring flames.

In the blue radiation image on the right side of Fig. 5, the darker core delineating the LOX jet can be seen up to the end of the window, because it absorbs radiation from the reaction zone on its far side. Thus, the integrated line-of-sight intensity from the shear layers on either side of the LOX core is far greater than from the foreground in front of the core.

The thin shear layer can be seen extending from the injection plane in both images. The path of the LOX core can be followed in the blue radiation image. The rapid spreading of the reaction zone can be well traced in the $\mathrm{OH}^{*}$ image, and indicates that flame-flame interaction becomes relevant after a few injector diameters downstream. Thus, the two images provide complementary information on the flame topology. 


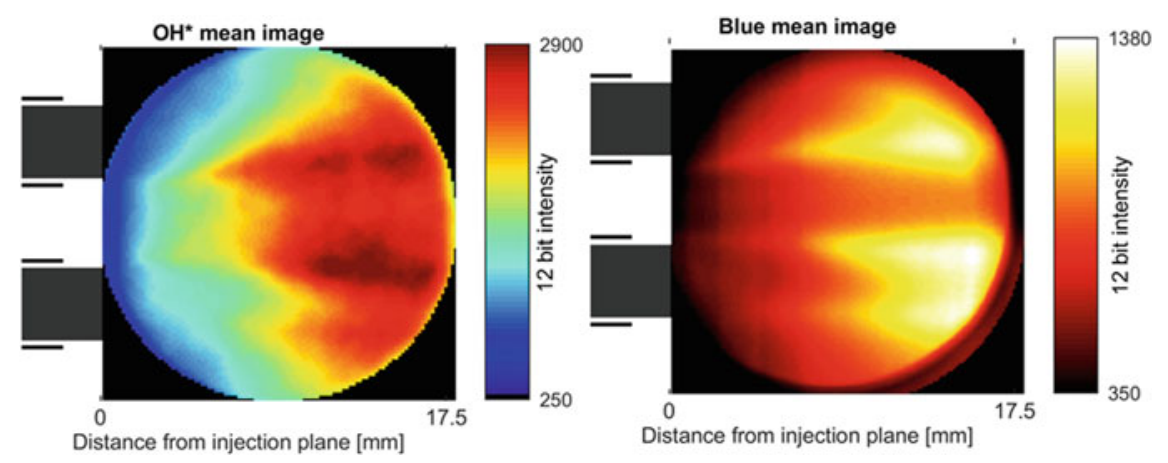

Fig. 5 Time-averaged $\mathrm{OH}^{*}$ image (left) and blue radiation image (right), both in false colour

\subsection{Dynamic Characteristics}

Figure 6 shows the DMD mode energies for both the $\mathrm{OH}^{*}$ and blue radiation data. The expected $1 \mathrm{~L}$ and $2 \mathrm{~L}$ mode frequencies of the LOX posts are also indicated by grey background areas. At the frequency of the $1 \mathrm{~L}$ mode around $5 \mathrm{kHz}$ there is only a low, broad peak in both data sets. At about $10 \mathrm{kHz}$, two distinct and sharp peaks can be detected. Analysis of the pressure oscillation sensors showed that the peak at $10.4 \mathrm{kHz}$ is the chamber $1 \mathrm{~T}$ mode, whereas the peak at $10.2 \mathrm{kHz}$ is the flame response to the LOX post $2 \mathrm{~L}$ mode.

The LOX post $2 \mathrm{~L}$ mode and chamber $1 \mathrm{~T}$ mode frequencies are not perfectly matched, leading to a weaker driving of the $1 \mathrm{~T}$ mode. The relative $1 \mathrm{~T}$ amplitude is below $1 \%$ of $p_{c c}$ and can therefore be described as stable $[9,26]$. Nevertheless, it was the goal of this study to investigate the flame response to LOX injector acoustics without the influence of the chamber $1 \mathrm{~T}$ mode. For that reason, the larger frequency spacing between LOX post $2 \mathrm{~L}$ and chamber $1 \mathrm{~T}$ mode is advantageous.

Fig. 6 DMD mode energies for $\mathrm{OH}^{*}$ and blue radiation imaging. The expected frequency range of the LOX post $1 \mathrm{~L}$ and $2 \mathrm{~L}$ modes are also indicated

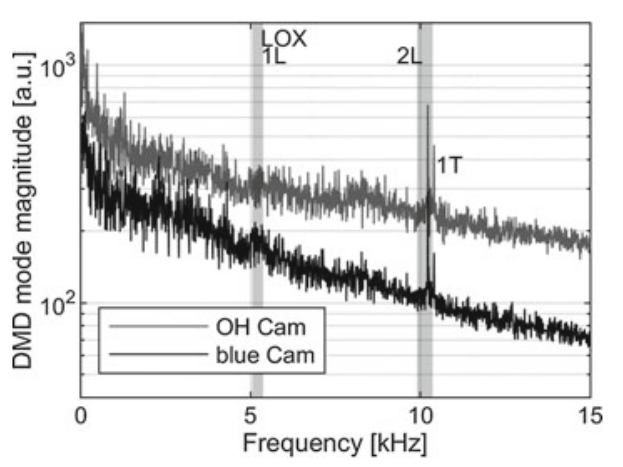




\subsection{LOX Core Dynamic Response to Excited Injector Eigenmodes}

Spatial mode shapes of the flame dynamics in $\mathrm{OH}^{*}$ and blue radiation at the acoustic eigenfrequencies of the LOX posts can be found in Ref. [2]. However, from the DMD spatial modes it is difficult to understand the dynamics of the flame which lead to the intensity variation in the longitudinal direction. For that reason, the DMD spatial mode has been combined with the mean flame image after increasing its relative intensity. The resulting flame response to the LOX post $1 \mathrm{~L}$ (left) and the LOX post $2 \mathrm{~L}$ mode (right), respectively can be found in Fig. 7. The discussion here is confined to the blue radiation images, where both the LOX core and the reaction zone surrounding it can be discerned.

The standing waves in the injectors lead to periodic variation of the injected LOX mass flow rate, producing bulging packets of LOX separated by narrower stems. This results in the appearance of wave-like structures on the surface of the dense LOX core when viewed from the side. The wave crests travel downstream with the convective speed of the LOX core. In the first two-thirds of the field-of-view, the wave-like structures on the LOX core seem to be symmetric. Further downstream, asymmetry in the wave pattern between the upper and lower sides of the core develops. The flow field in the combustion chamber is accelerated by the expanding gases from combustion, and local variations in the flow field may be responsible for this asymmetry.

The initially symmetrical character of the LOX core pulsation is consistent with a periodic variation in the rate of the injection [18, 27]. A LOX core response to transverse perturbations from the chamber would appear more sinusoidal [3, 12]. Therefore, the presented LOX core dynamics are in agreement with the LOX-side injection-coupling mechanism hypothesised by Gröning. [10].
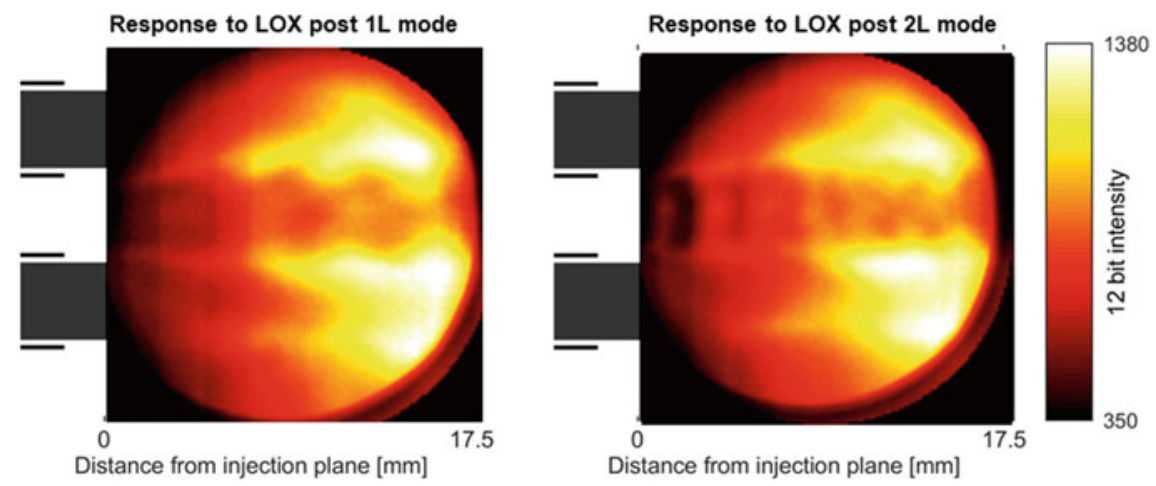

Fig. 7 Flame response in blue radiation to the LOX post $1 \mathrm{~L}$ mode at about $5 \mathrm{kHz}$ (left) and the LOX post $2 \mathrm{~L}$ mode about $10 \mathrm{kHz}$ (right) 
Fig. 8 Sketch of a modified BKD LOX injector with an acoustic absorber connected to the LOX post. Modified from [1]

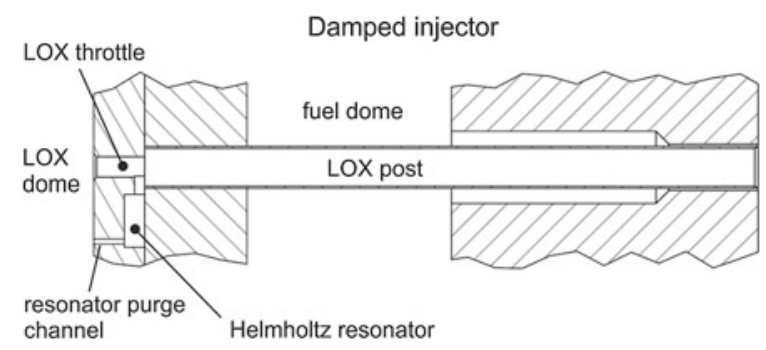

\subsection{Damping Device to Reduce Risk of Injection-Coupled Instabilities}

Based on the identification of the coupling mechanism in BKD, it was possible to devise a new method to reduce the impact of injection-coupled combustion instabilities. The new damping method is characterised by acoustic resonators which are connected to the LOX posts, as illustrated in Fig. 8. Instead of damping the pressure oscillation of the instability in the chamber, the resonators are tuned on the acoustic modes of the injection elements. To the author's knowledge this study presents the first damping device which aims at reducing the driving of high-frequency combustion instabilities in LPREs instead of the resulting chamber pressure oscillations.

An important design feature of the device are small diameter purging holes which connect the resonator volumes with the injector manifold. This ensures that there is the same speed of sound in the resonators and in the injectors, which drastically simplifies tuning of the resonators [1].

The effect of the damped LOX posts on the instability has been tested experimentally and the results were compared with a test run with the original injector design. It could be shown that the damped LOX post inlet throttles had no effect on combustion performance or injection pressure drop [1], while successfully reducing the instability amplitude. Figure 9 shows an averaged PSD of all eight p' sensors in

Fig. 9 Comparison of chamber pressure PSDs for standard and damped injector configurations for the same operating condition [1]

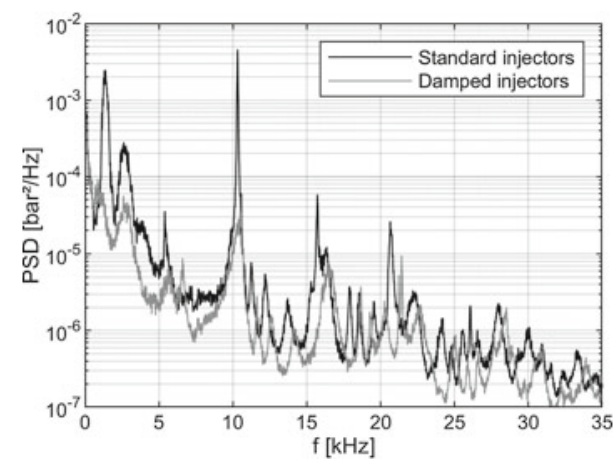


the measurement ring for the previously unstable operating condition of $p_{c c} 80 \mathrm{bar}$ and ROF 6 with standard BKD injectors. By comparison, the peak of the $1 \mathrm{~T}$ mode at $10 \mathrm{kHz}$ is significantly reduced with the damped injector.

\section{Summary and Conclusions}

The DLR research combustor BKD shows self-excited combustion instabilities of the $1 \mathrm{~T}$ mode type for certain operating conditions under highly representative conditions and therefore offers a valuable platform for the investigation of the underlying coupling mechanism. In previous studies the driving mechanism of the instability was identified as LOX post injection-coupling. This type of coupling mechanism is not uncommon for cryogenic rocket engines. For that reason, the BKD injectioncoupling mechanism was studied in further detail, in particular the flame response to the acoustic oscillations in the LOX posts, in order to be able to prevent this type of instability in future rocket engines. The flame response was visualised via a window providing optical access to the combustion chamber, where conditions are characterised by pressures up to 80 bar and temperatures up to $3600 \mathrm{~K}$. High-speed imaging of the well-known $\mathrm{OH}^{*}$ radiation as well as blue radiation were recorded simultaneously.

The flame dynamics were investigated by Dynamic Mode Decomposition (DMD). For some operating conditions, the DMD mode energy spectra showed peaks at the eigenmodes of the LOX posts. The spatial modes showed a longitudinal and symmetric variation in the intensity distribution. This observation can be explained by periodic mass flow rate oscillations of the injected LOX and therefore further supports the hypothesis of an injection-driven modulation of the heat release rate oscillation of the flames.

Based on the gained understanding of the coupling mechanism of the BKD combustion instability, a new damping device to reduce the risk of injection-coupled instabilities was developed. The basic idea of the new damping device is to damp the injector acoustic modes with absorbers, instead of damping the instability itself in the combustion chamber. The new device was tested in BKD and the results showed that the amplitude of the chamber pressure oscillations was successfully reduced. This invention has the potential to reduce the risk posed by injection-coupled combustion instabilities in future cryogenic rocket engines with shear coaxial injection elements.

Acknowledgements Financial support has been provided by the German Research Foundation (DFG) in the framework of the SFB TRR40 Cooperative Research Centre. The work is also associated with the French-German Rocket Engine Stability iniTiative (REST). The authors would like to thank the crew of the P8 as well as Robert Stützer and Alex Grebe for setting up the optical diagnostics. The research conducted by Thomas Fiala and Stefan Gröning within the second funding period of the SFB TRR40 are also greatly acknowledged. 


\section{References}

1. Armbruster, W., Hardi, J.S., Miene, Y., Suslov, D., Oschwald, M.: Damping device to reduce the risk of injection-coupled combustion instabilities in liquid propellant rocket engines. Acta Astronaut. 169, 170-179 (2020). https://doi.org/10.1016/j.actaastro.2019.11.040

2. Armbruster, W., Hardi, J.S., Suslov, D., Oschwald, M.: Injector-driven flame dynamics in a high-pressure multi-element oxygen-hydrogen rocket thrust chamber. J. Propul. Power 35(3), 632-644 (2019). https://doi.org/10.2514/1.B37406

3. Beinke, S., Tonti, F., Karl, S., Hardi, J., Oschwald, M., Dally, B.: Modelling flame response of a co-axial LOx/GH2 injection element to high frequency acoustic forcing. In: 7th EUCASS. Milano, Italy (2017). https://doi.org/10.13009/EUCASS2017-172

4. Beinke, S.K.: Anaylses of flame response to acoustic forcing in a rocket combustor. Ph.D. thesis, The University of Adelaide, Australia (2017)

5. Fiala, T.: Radiation from high pressure hydrogen-oxygen flames and its use in assessing rocket combustion instability. Ph.D. thesis, Technical University of Munich, Munich, Germany (2015)

6. Fiala, T., Sattelmayer, T.: Assessment of existing and new modeling strategies for the simulation of $\mathrm{OH}^{*}$ radiation in high-temperature flames. CEAS Space Journal 8(1), 47-58 (2016). https:// doi.org/10.1007/s12567-015-0107-z

7. Fiala, T., Sattelmayer, T., Gröning, S., Hardi, J., Stützer, R., Webster, S., Oschwald, M.: Comparison between excited hydroxyl radical and blue radiation from hydrogen rocket combustion. J. Propul. Power 33(2), 490-500 (2017). https://doi.org/10.2514/1.B36280

8. Gaydon, A.: The Spectroscopy of Flames. Chapman and Hall, London (1957)

9. Gröning, S.: Untersuchung selbsterregter Verbrennungsinstabilitäten in einer Raketenbrennkammer. Ph.D. thesis, RWTH Aachen (2017)

10. Gröning, S., Hardi, J.S., Suslov, D., Oschwald, M.: Injector-driven combustion instabilities in a Hydrogen/Oxygen rocket combustor. J. Propul. Power 32(3), 560-573 (2016). https://doi. org/10.2514/1.B35768

11. Gröning, S., Hardi, J.S., Suslov, D., Oschwald, M.: Measuring the phase between fluctuating pressure and flame radiation intensity in a cylindrical combustion chamber. Prog. Propul. Phys. 11, 425-446 (2019). https://doi.org/10.1051/eucass/201911425

12. Hakim, L., Schmitt, T., Ducruix, S., Cuenot, B., Candel, S.: Dynamics of a transcritical coaxial flame under a high-frequency transverse acoustic forcing: Influence of the modulation frequency on the flame response. Combust. Flame 162(10), 3482-3502 (2015). https://doi.org/ 10.1016/j.combustflame.2015.05.022

13. Hardi, J.S., Beinke, S.K., Oschwald, M., Dally, B.B.: Coupling of cryogenic oxygen-hydrogen flames to longitudinal and transverse acoustic instabilities. J. Propul. Power 30(4), 991-1004 (2014). https://doi.org/10.2514/1.B35003

14. Hardi, J.S., Hallum, W.Z., Huang, C., Anderson, W.E.: Approaches for comparing numerical simulation of combustion instability and flame imaging. J. Propul. Power 32(2), 279-294 (2016). https://doi.org/10.2514/1.B35780

15. Harrje, D., Reardon, F. (eds.): Liquid Propellant Rocket Combustion Instability, NASA SP-194 (1972)

16. Huang, C., Anderson, W.E., Harvazinski, M.E., Sankaran, V.: Analysis of self-excited combustion instabilities using decomposition techniques. AIAA J. 54, 2791-2807 (2016). https:// doi.org/10.2514/1.J054557

17. Kawashima, H., Kobayashi, K., Tomita, T.: A combustion instability phenomenon on a LOX/Methane subscale combustor. In: 46th AIAA/ASME/SAE/ASEE Joint Propulsion Conference \& Exhibit 2010. Nashville, Tennessee (2010). https://doi.org/10.2514/6.2010-7082

18. Nez, R., Schmitt, T., Ducruix, S.: High-frequency combustion instabilities in liquid rocket engines driven by propellants flow rate oscillations. In: Space Propulsion 2018. Seville, Spain (2018)

19. Nunome, Y., Onodera, T., Sasaki, M., Tomita, T., Kobayashi, K., Daimon, Y.: Combustion instability phenomena observed during cryogenic hydrogen injection temperature ramping 
tests for single coaxial injector elements. In: 47th AIAA/ASME/SAE/ASEE Joint Propulsion Conference \& Exhibit 2011. San Diego, California (2011). https://doi.org/10.2514/6.20116027

20. Oefelein, J.C., Yang, V.: Comprehensive review of liquid-propellant combustion instabilities in F-1 engines. J. Propul. Power 9(5), 657-677 (1993). https://doi.org/10.2514/3.23674

21. Oschwald, M., Knapp, B.: Investigation of combustion chamber acoustics and its interaction with LOX/H2 spray flames. Prog. Propul. Phys. 1, 205-224 (2009). https://doi.org/10.1051/ eucass/200901205

22. Rayleigh, J.W.S.: The explanation of certain acoustical phenomena. Nature 18(455), 319-321 (1878)

23. Rey, C., Ducruix, S., Richecoeur, F., Scouflaire, P., Vingert, L., Candel, S.: High frequency combustion instabilities associated with collective interactions in liquid propulsion. In: 40th AIAA/ASME/SAE/ASEE Joint Propulsion Conference and Exhibit. AIAA Paper 2004-3518, Fourt Lauderdale, Florida (2004). https://doi.org/10.2514/6.2004-3518

24. Schmid, P.J.: Dynamic mode decomposition of numerical and experimental data. J. Fluid Mech. 656, 5-28 (2010). https://doi.org/10.1017/S0022112010001217

25. Schulze, M.: Linear stability assessment of a cryogenic rocket engines. Ph.D. thesis, TU Munich, Munich, Germany (2016)

26. Sutton, G.P., Biblarz, O.: Rocket Propulsion Elements, 8th edn. Wiley, New York (2010)

27. Urbano, A., Douasbin, Q., Selle, L.: Analysis of coaxial-flame response during transverse combustion instability. In: 7th EUCASS. Milano, Italy (2017). DOI https://doi.org/10.13009/ EUCASS2017-609

28. Watanabe, D., Tamura, T., Onga, T., Manako, H., Negoro, N., Kurosu, A., Kobayashi, T., Okita, K.: Hot-fire testing of LE-X thrust chamber assembly. In: 30th ISTS. Kobe, Japan (2015)

29. Wierman, M., Pomeroy, B., Anderson, W.: Development of combustion response functions in a subscale high pressure transverse combustor. Prog. Propul. Phys. 8, 55-74 (2016). https:// doi.org/10.1051/eucass/201608055

30. Yang, V., Anderson, W. (eds.): Liquid Rocket Engine Combustion Instability. American Institute of Aeronautics and Astronautics, Washington, DC (1995)

Open Access This chapter is licensed under the terms of the Creative Commons Attribution 4.0 International License (http://creativecommons.org/licenses/by/4.0/), which permits use, sharing, adaptation, distribution and reproduction in any medium or format, as long as you give appropriate credit to the original author(s) and the source, provide a link to the Creative Commons license and indicate if changes were made.

The images or other third party material in this chapter are included in the chapter's Creative Commons license, unless indicated otherwise in a credit line to the material. If material is not included in the chapter's Creative Commons license and your intended use is not permitted by statutory regulation or exceeds the permitted use, you will need to obtain permission directly from the copyright holder.

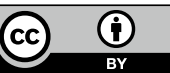

